تأثثير تدريبات الكروس فيت (cross fit ) علي بعض لقدرات البانية و المستوي الرقمي

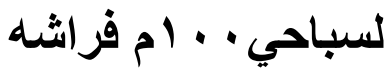

م.د / مصطفى سمير محمد

قسم التدريب الرياضي بكلية التربية

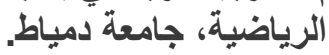

مقدمة و مشكله البحث:

يسعي التدريب الرياضي الي تطـوير وتوجيـه القدرة البدنيـة والفنيـة للفـرد الرياضـي نحـو

تحقيق أعلي مستوي ممكن ، حيث أن التطور العلمي في مختلف علوم الرياضة أضاف كثير ا مـن

أساليب وطرق التدريب الحديثة التي يمكن الاستفادة منها في تحسين فعالية عملية التدريب، ومـن أهم هذه الطرق الحديثة الكروس فيت (cross fit) و استخدامه في تنمية القوة العضلية والسرعة وبعض القدر ات البدنية الخاصة ليس في السباحة فقط ولكن في مختلف الرياضـات، حيـث أن الإعداد البدني للسـباحين أصسبح مـن أهـم الوسـائل لتحسـين المسـتوي الرقمـي، وخاصـة في ظلـ استخدام البعض لتدريبات القوة التقليدية التي بـدأت تصـيب السباحين بالملل وكونـت لـدي بعض منهم كر اهية شديدة للتدريب الأرضـي مدـا دفع بعض الناثـئين في المر احل العمريـة المختلفـة لإهمال التدريب الأرضي و عدم رغبتهم في تحقيق أزمنة قياسية، كما دفعت البعض الأخر لترك رياضية السباحة ،لذا كان من الضروري إيجاد طريقة علمية وأمنة لزيادة القوة العضلية و القدرات البدنية الخاصة بالسباحة وفي نفس الوقت قـادرة علي جذب السباحين علي التـريب الأرضسي فأصبح السباحين الممارسين للكروس فيت (cross fit) يمارسـون رياضتين في أن واحد وفي نفس الوقت يجدون الجسم المتميز الذين يريدون الحصول عليه وتحقيق الأزمنة القياسية والوصول للإنجاز .

و يثير" ماجلشيو " ( r . . r ) انا التذريبات الأرضية ضرورية من اجل تحقيق الاعداد الثـامل للسـباح و لـذا وجـب على السـباح الجمـع بـين التـدريبات الأرضـية و التـي تتشـابه مـع التدريبات المائية من حيـث مسـتوى الثـدة المستخدمة بهدف تحقيتق التنميـة الثـاملة و الوصـول لأعلى مستوى من التكيف التدريبي و الارتقاء بالمستوى الرقمي . ( 24 : با7 ا ) ويري أشرف محمد جمعة" (9 1 ـ أن أن عدم كفاية القوة العضلية يؤثز سلبا علي مسنوي إتقان وتطوير الأداء المهارى في السباحة حيث أن جسم السباح يتحرك للأمام عن طريق محصلة 
القوة الناتجة عن حركات الذر اعين وضربات الرجلين متخذا الوضع الأفقي داخل الماء لـللك فـأن أداء المهار ات الخاصة بالسباحة يتطلب حد أقصي من القوة العضلية ( 5: ror )

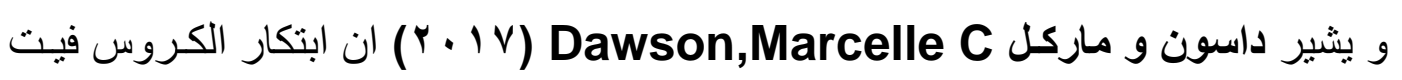
كأسلوب تدريبي ينسب الى لاعب الجمبـاز السـابث جريج غلاسـمان و اول افتتاح (crossfit) لصاله رياضيه خاصه بتدريبات الكروس فيت (cross fit) في سانتا كروز عـام 1990 م كمـا انتشـرت حـول العـالم في اكثر مـن . . . . نـادى رياضـي نتيجـة لاعتمادهـا و اجـر اء بعض

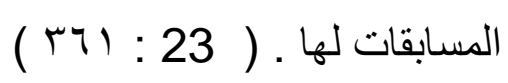

ويتفق كل من ماتي مونيوز وآخرون . IV) Maté-Muñoz, et al ( • م) ، وسـميث

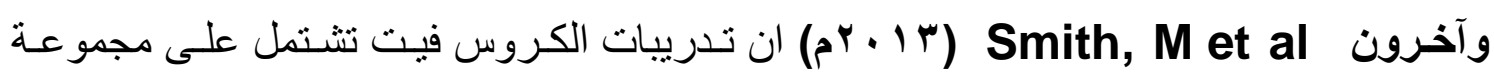
متنو عة مـن التـدريبات التـي تمــارس بشـل دائربي بهدف تتميـة القدر ات البدنيـة لتطوير الأداء الرياضي وأيضا ، تلعب رياضة الكروس فيت دورًا مهماً في تحسين اللياقة البدنية و القوة . $($ (rY:r.)( $): 27)$

ويشير أحمد عوض حسن (9 1 • r) أن الكروس فيت طريقة معاصـرة لتدريب القدر ات البدنية دن خلال تعزيز اللياقة البدنية بشكل عام من تطوير القدر ات الهو ائبـة والتحمـل والسـرعة و التوازن و القوة عن طريق رفع الأثقال والجمباز الذي يتم بأداء معقد. ( 18 : 2 ) ويذكر عصـام حلمى ( 1991 ) أن العديـد مـن البـاحثين و المتخصصسين في المجـال الرياضي يتفقوا على وجود ارتباط قوى بين القدرات البدنية وبين مستوى الأداء المهارى، فالفرد الرياضي لا يستطيع إتقان المهار ات الأساسية لنوع النشاط الرياضي الذي يتخصص فيه في حالة افتقاره للقدر ات البدنية لهذا النوع من النشاط.( 12: 0 ( ) )

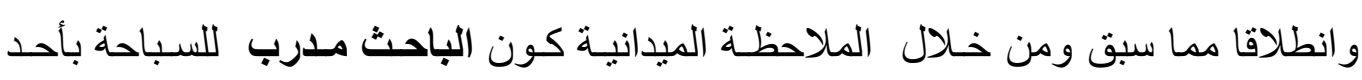
الأندية الرياضية بالدقهلية مـن خـلال ملاحظتـه للفروق الملحوظـة في القدرات البدنيـة الخاصـة بالسباحين على مستوى المحافظة و باقي السباحين على مستوى الجمهوريـة و خاصـه العاصــة على الرغم مـن أن أسـلوب السـباحة وفنيـات الأداء متقاربـة الى حد كبيـر وقد يكون هنـاك تطابق.و الذى قد يكون نتيجة بعض المتغير ات المـؤثرة و التي قد يكـون منهـا تجاهل العديــ من المدربين تطبيق تدريبات المقاومة او ان معظم البر امج التدريبيـة الخاصـة بتنميـة القوة العضـلية للسباحين تركز فقط على تدريبات الأثقال داخل صـالات الإثقال دون توجيـه تـدريبات المقاومـة بحيث تتشابه مع الأداء الحركي لنوع السباحة التخصصي و كذللك نظـام الطاقـة المسـتخدم ومـن خلال الاطلاع على ما أتيح للباحث من در اسـات سابقة والاطلاع على شـبكة المعلومـات الدوليـة 
(الانترنتا) ، قرر الباحث استخدام تـريبات الكروس فيت (cross fit) كمحاولـه للارتقـاء بمستوى القدر ات البدنية للسباحين و المستوى الرقمي .

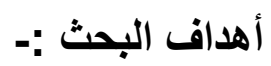

يهاف البحث الى التعرف على تأثير تدريبات الكروس فيت (cross fit) على بعض المتغيرات البذنية والمستوى الرقمي للسباحين من خلال: 1 - تصميم برنامج تدريبي ارضي باستخدام تدريبات الكروس فيت هنيت (cross fit)

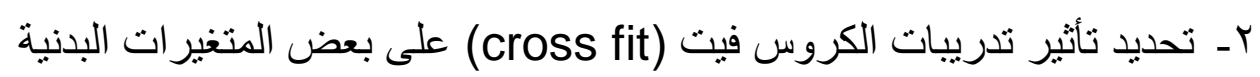

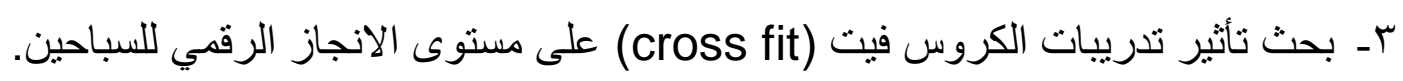

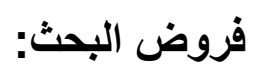

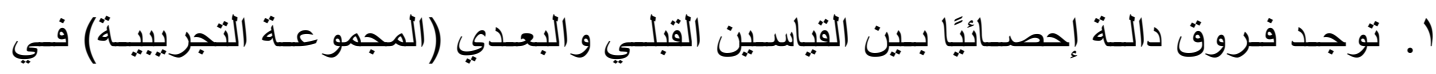

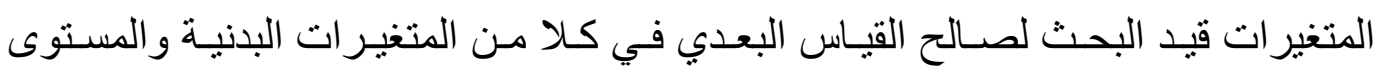
الرقمي. r. توجد فروق دالة إحصائيًا بين القياسين القبلي و البعدي (المجموعة الضابطة) في المتغيرات

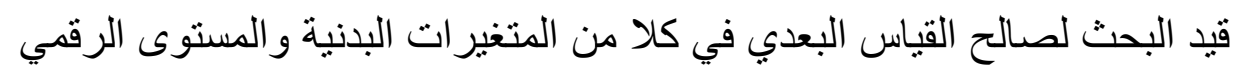

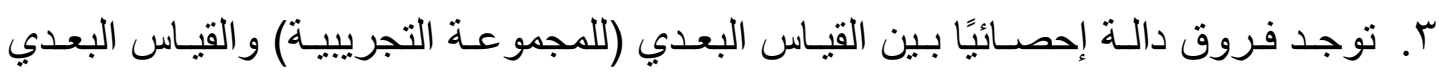

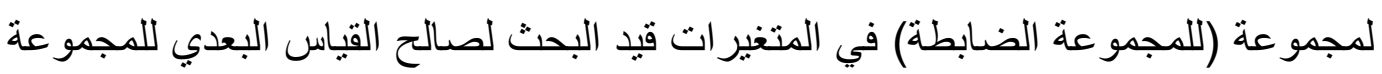
التجريبية. المصطلحات المستخدمة في البحث:

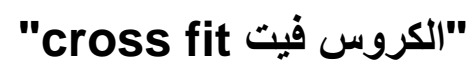
- هو أحد الأساليب التدريبية الحديثة والتي تجمع بين أكثر من أسلوب تدريبي وأداة رياضية

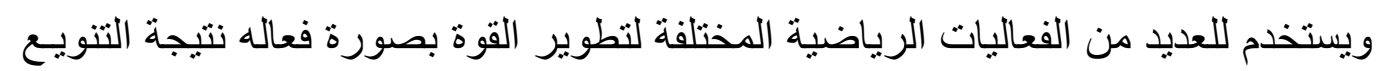
فى الاستثارة ودرجة الثدة لتحقيق عمليات التكيف بأعلى معدلات النمو و التطور . $(1:$ ro)

- هو اتجاه تدريب وظيفي يعتمد على الأداء البشري لعدد من الحركات التي تشـمل الجسم

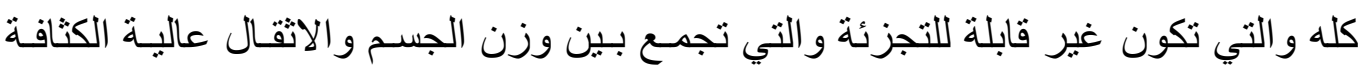

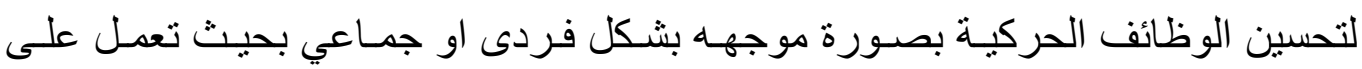
$(0: r \cdot)$ تحسين القدر ات البدنية و الحركية للاعبين. 
1 - وجدان سامي عبد الحميا محمد (9 ( • r) ( 19 ) )" تأثير تدريبات الكروس فيت علي الكفاعة البدنية و المستوي الرقمي لسباحي ، . عمنر حرة " وكان من أهم أهداف الدراسـة التعرف علي تأثثير مجموعة من تـدريبات الكروس فيت علي الكفـاءة البدنيـة و المستوي الرقمي لسباحي · · عمتر حرة وقد استخدمت الباحثة المنهج التجريبي باسـتخدام التصـميم التجريبـي لمجمـوعتين إحـداهما (ضــابطة) و إحـداهما (تجريبيـة) وقـد بلــن حجـم العينـة

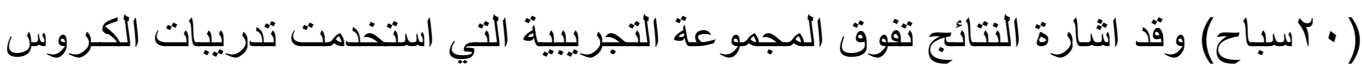
فيت عن المجموعة التي استخدمت التدريبات العادية.

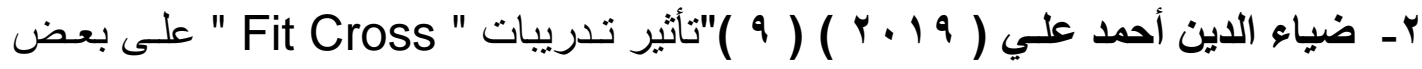
المتغير ات البدنية و المهار ات الأساسية لليد غير المفضلة لـدى أثنبال كرة اليد "و كـان هدف البحث التعرف على تأثير تدريبات الكروس فيـت ( cross fit ) على المغيرات البدنية و المهارية لناشئي كرة البد وقد استخدم الباحث المنهج التجريبي باستخدام التصميم التجريبي لمجمو عتين إحداهما (تجريبية) و الأخرى (ضابطة) وبلغت العينة ـ ب لاعب من اشبال كرة اليد و قد إثـار ات النتائج الى وجود دلالات إحصائية بين متوسطات القياسـات القبلية و البعدية لكل من المجمو عتين لصـالح القياسـات البعديـة للمجموعـة التجريبيـة ممـا يعني تفوق المجموعة المستخدمة لتدريبات الكروس فيت ( cross fit )

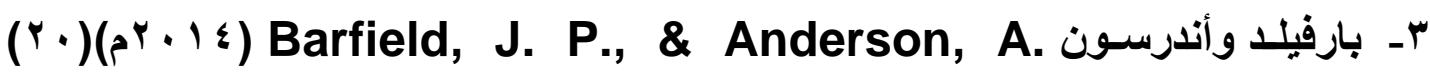
بعنوان تأثير تدريبات الكروس فيت ( cross fit )على اللياقة البدنيـة المرتبطـة بالصـحة

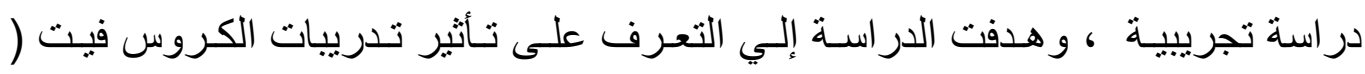
(cross fit التجريبي كوبلغ عدد أفراد عينة البحث ، ه لاعب ، وتم تتفيذ البرنامج التدريبي لمدة با أسبوع ، وكان مـن أهـم النتـائج وجـود فروق ذات دلالـة إحصـائية في متغيـرات القدرة الهو ائية و التحمل العضلي. 
اسـتخدم الباحث المـنهج التجريبي وذلك لملائمتهـه لتطبيـق البحث وباسـتخدام التصـيم

التجريبي ذو القياس القبلي والبعدي لمجموعتين إحداهما تجريبية والأخرى ضابطة

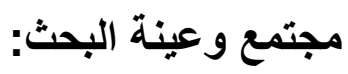

يمثل مجتمع البحث السباحين الناثـئين بفريـق السباحة العمـومي بنـادي الحـوار للمرحلـة السنية ( 10 _ 17 ) سنه و المسجلين بالاتحاد المصري للسباحة

عينة البحث:

تم اختيار عينة البحث بالطريقة العدية من سباحي نادي الحـوار الرياضـي تحت 17 سـنة

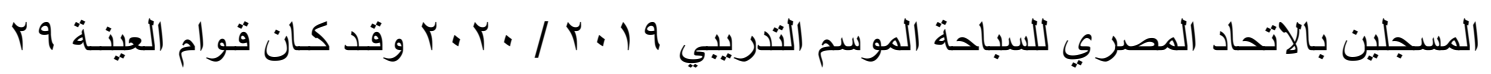
سباح وقد تم اجر اء الدر اســة الاســطلاعية على (0) سباحين ثـم تـم اسـتبعاد (ع ) سباحين لعدم

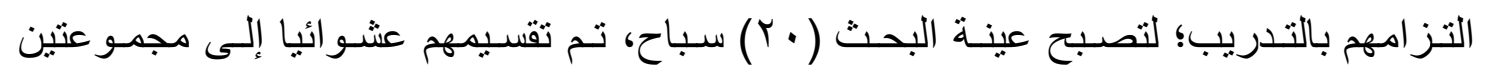
متساويتين إحدا هما تجريبية والأخرى ضابطة قو ام كل عينة ( • () ناشـئين، وقد أجرى الباحث. التجانس في الطول و الوزن و العمر الزمني وجدول ( ) جدول (1) توصيف عينة البحث

\begin{tabular}{|c|c|c|c|c|}
\hline \multirow{2}{*}{ البرنامج } & \multicolumn{3}{|c|}{ العينة } & \multirow{2}{*}{ p } \\
\hline & النسبة & 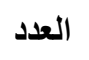 & نوع العينة & \\
\hline البرنامج المقترح & 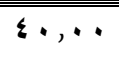 & 1. & المجموعة التجريبية & 1 \\
\hline البرنامج المتبع & $\varepsilon \cdot, \cdots$ & 1. & المجموعة الضابطة & $r$ \\
\hline- & $r \cdot, \cdots$ & 0 & المجموعة الاستطلاعية & $r$ \\
\hline- & $\% 1 \ldots$ & Yo & العينة الكلية للبحث & \\
\hline
\end{tabular}
التحقق من اعثدالية توزيع العينة الكلية للبحث:

للتأكـد مـن تجـانس العينـة الكليـة للبحــث (ب0) سـبـاح (المجمو عـة التجريبيـة و المجموعـة الضابطة و المجموعة الاستطلاعية)؛ قام الباحث بعمل بعض القياسات، للتأكد من اعتداليـة توزيـع البيانات بين أفر اد العينة في المتغيرات قيد البحث، كما هو موضح في جدول (Y) 
جدول (Y) المتوسطات الحسابية والوسيط والانحر افات المعيارية ومعاملات الالتواء للعينة الكلية للبحث في المتغيرات قيد البحث

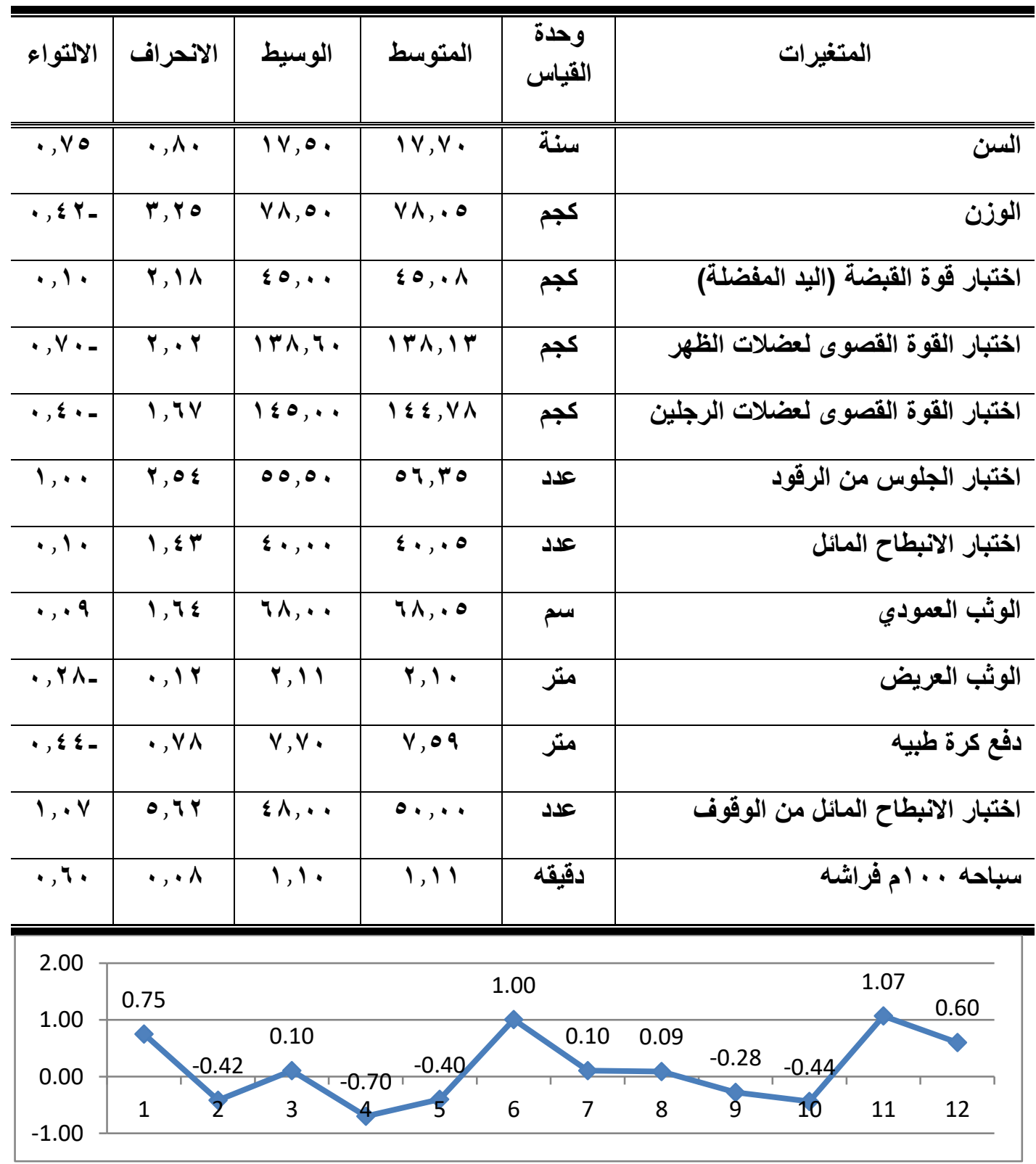

شكل ( 1 ) معامل الالتواء لعينة البحث في المتغيرات قيد البحث.

يتضح من جدول(Y)، وشكل( () أن قيم معاملات الالتواء انحصـرت مـا بين (r-r) و(r) مما يدل على أن قياسات العينة الكلية للبحث في المتغير ات قيد البحث قد وقعـت تحت المنحنى الاعتدالي و هذا يدل على تجانس أفر اد عينة البحث الكلية في هذه المتغير ات. 
قام الباحـث بـأجر اء التكـافؤ بـين (المجموعـة التجريبيـة و المجموعـة الضـابطة) فى ضــــ المتغير ات قيد البحث والتـي قد تـؤثر على البحث ويوضـح جدول (ب) تكـافؤ المجمـوعتين في

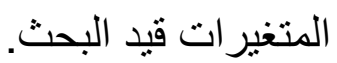

جدول (r) تكافؤ مجموعتي البحث (التجريبية والضابطة) في الاختبارات قيد البحث $1 \cdot=r \dot{0}=1 \dot{0}$

\begin{tabular}{|c|c|c|c|c|c|c|}
\hline \multirow[b]{2}{*}{ قيمة } & \multicolumn{2}{|c|}{ المجموعة الضابطة } & \multicolumn{2}{|c|}{ المجموعة التجريبية } & \multirow[b]{2}{*}{ القياس } & \multirow[b]{2}{*}{ المتغيرات } \\
\hline & ف الانحرا & (سنَ) & ف الانحرا & المتوسط & & \\
\hline 1,79 & $1,7 \varepsilon$ & $\varepsilon \leqslant, \mu$ & $r, \varepsilon 0$ & $\leqslant 0, \wedge \theta$ & 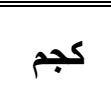 & اختبار قوة القبضة (اليال \\
\hline$\cdot, r \wedge$ & $r, r_{1}$ & $\begin{array}{c}1+\Lambda, r \\
r\end{array}$ & $1, \times 9$ & Irs, & 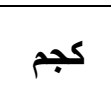 & اختبار القوة القصوى لعضلات \\
\hline $1, \ldots$ & $\cdot, \wedge \varepsilon$ & $\begin{array}{c}1 \leq \varepsilon, \varepsilon \\
.\end{array}$ & $Y, Y_{1}$ & $\begin{array}{c}1 \leq 0,1 \\
0\end{array}$ & 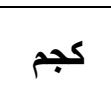 & اختبار القوة القصوى لعضلات \\
\hline$\cdot, 9 \mathrm{~V}$ & $r, r_{0}$ & $\Delta \Delta, \Lambda$. & $r, V r$ & $09,9$. & عدد & اختبار الجلوس من الرقود \\
\hline$\cdot, \mathrm{VV}$ & $1, \varepsilon$ & $r q, \wedge$. & $1, \leqslant 9$ & $\varepsilon \cdot$, & عدد & اختبار الانبطاح المائل \\
\hline$\cdot, 14$ & $1, \wedge 9$ & $7 \Lambda, \ldots$ & $1, \leqslant 0$ & $7 \wedge, 1$. & سم & الوثب العمودي \\
\hline$\cdot, \wedge$. & $\cdot, I r$ & $r, \cdot \Lambda$ & $\cdot, 14$ & $r, I r$ & 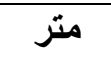 & الوثب العريض \\
\hline., 09 & $\cdot, \mathrm{VV}$ & $V, \leqslant 9$ & $\cdot, \Lambda Y$ & $v, 79$ & متر & دفع كرة طبيه \\
\hline$\cdot, \mu_{1}$ & $0, r$ & $\leqslant 9,7$. & $7,1 \%$ & $0, \ldots$ & 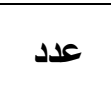 & اختبار الانبطاح المائل من \\
\hline$\cdot, O r$ & $\cdot, 11$ & $1,1 Y$ & $\cdot, .0$ & 1,1 . & دقيقه & سباحه . . . ام فر اشذه \\
\hline
\end{tabular}

يتضح مـن جدول (r) عدم وجـود فروق ذات دلالـة إحصـائية بـين القياسـات قيد البحـث للمجمو عتين التجريبيتين حيث كانت قيمة (ت) المحسوبة أقل مسن قيمتهـا الجدوليـة عند مسـتوى 
معنويـة (0 . , •)، ممـا بـدل على عـدم وجـود فـروق دالـة إحصـائية بـين القياسـات في جميـع الاختبار ات، مما يشير الى تكافؤ المجموعتين في المتغير ات قيد البحث. وسائل وأدوات جمع البيانات:

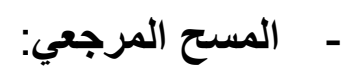

مـن خـلال مـا قـام الباحـث بـهـ مـن مسـح مرجعـي للعديـد مـن الأبحـاث و المر اجهع العربيـة و الأجنبية فقد توصل إلى أنسب الاختبار ات والقياسات التي تحقق هدف البحث. - القياسـات الأساسية والاختبارات البدنية وقياسات المستوى الرقمي لسباحه .. 1 متر فزاشه:

من خلال المسح المرجعي للعديد من الدراسات والبحوث العربية والأجنبية في مجال تدريب السباحة تم تحديد القدر ات البدنية الحركية و البدنية الخاصة قيد البحث وتحديد كيفية قياسها. القياسات الأساسية والخاصة بتوصيف وتجانس عينة البحث وهي: السن (لأقرب نصف سنه) -الوزن (لأقرب كيلو جرام) -الطول (لأقرب سنتيمنر). العمر التدريبي (لأقرب نصف سنة).

الخطوات التنفيذية :

قام الباحث باتباع الخطوات التفيذية للبحث كالاتي: -

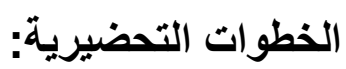

الحصول على موافقة من نادي الحـوار الرياضـي بالمنصـورة على تطبيـق الدراسـة على سباحي النادي حيث أن الباحث من الجهاز الفني للسباحة بالنادي تـم الاجتمـاع بالسباحين وأوليـاء الأمور , لتوضيح أهمية البحث, , والحصول على مو افقة أولياء الأمور على إجراء القياسات على السباحين .

الاراسة الاستطلاعية:

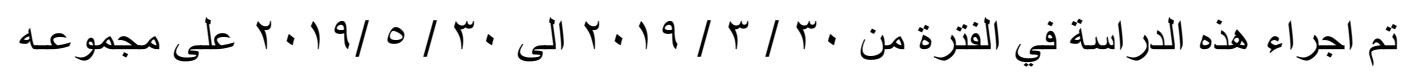
سباحين من خارج العينة الاساسية و عددهم (0) من نادى الحوار .

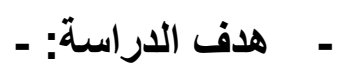

ا ـ تصميم استمارة تسجيل البيانات و القياسات الخاصة بكل سباح 
r- اكتشاف الصعوبات أثناء إجر اء القياسات لتحديد أفضل طرق القياس r- سر عه ضبط و إعداد الأجهزة والأدوات المستخدمة في إجر اء القياسات. ع- التأكد من صلاحية الأجهزة والأدوات المستخدمة في القياس. ○ـ التأكد من مناسبة الاختبار ات لأفراد عينة البحث.

7ـ تدريب المساعدين على أساليب القياس المستخدمة وكيفية إجراء تلك القياسات وترتيبها. Vـ التأكد من مناسبة الأحمال البدنية المستخدمة بالبرنامج لطبيعة المرحلة السنية.

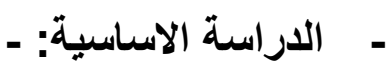

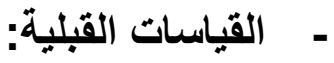

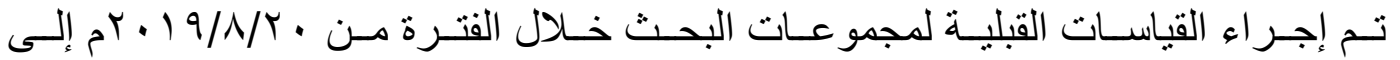
: 19/1/rq

جدول (ع) الجدول الزمنى لأجراء القياسات القبلية

\begin{tabular}{|c|c|c|}
\hline القياسات & اليوم & p \\
\hline فياس الطول والوزن. & 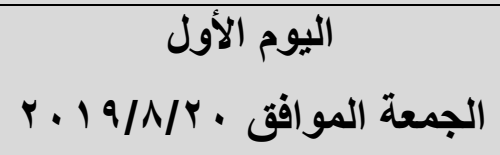 & 1 \\
\hline اختبار قياس قوة عضلات الظهر & 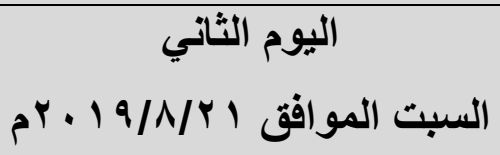 & $r$ \\
\hline 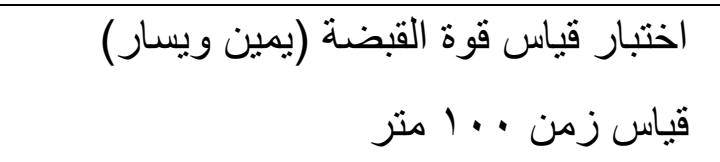 & 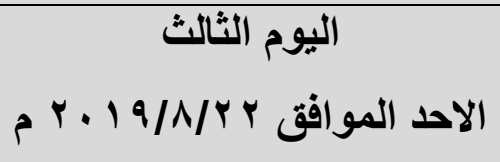 & $r$ \\
\hline 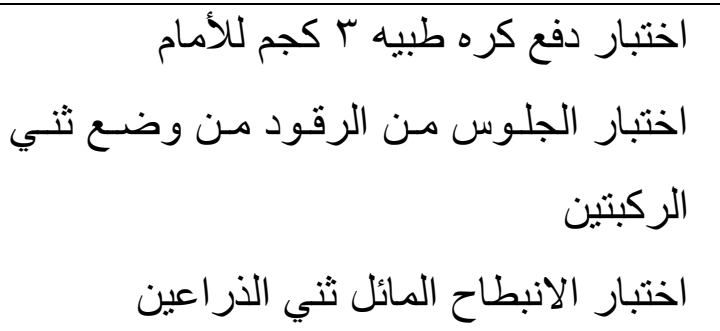 & 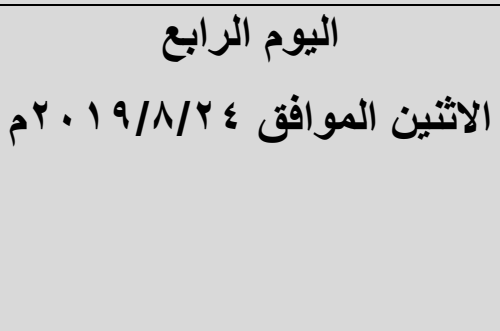 & $\varepsilon$ \\
\hline
\end{tabular}


( ) تصميم وتقنين محتويات البرنامج التدريبي:

قام الباحث بمسح للمر اجع العلمية المتخصصة في مجال تـريب السـباحة واسـتعان بالعديـ من المر اجع الحديثة في تصميم المجموعـات التدريبيـة الخاصـة بالتـدريبات الأرضـية للسباحين، و استغرق تطبيـق البرنـامج التـدريبي المقترح حومدته (^ أسـابيع) خـلال الموسـم التـدريبي (فترة (الاعداد الخاص)

$$
\text { ץ ) خطوات تصميم البرنامج التدريبي: }
$$

اتبع الباحث الخطوات التالية في تصميم برنامجه التدريبي:

$$
\text { ا (. تحديد هدف البرنامج. }
$$

Y r تحديد بدء ونهاية الفترة الزمنية للبرنامج.

r. . إجر اء الاختبار ات والمقاييس لتحديد مستوى اللاعبين.

$$
\text { ع. تحديد أسابيع فتر ات بداية ووسط ونهاية البرنامج. }
$$

๑. تحديد الزمن الكلى للتدريب وتوزيع الزمن على الإعدادات المختلفة.

7. تقسيم أزمنة كل إعداد على المحتوى الفني للبرنامج وفق ما يراه المدرب

\section{هدف البرنامج:}

حدد الباحث هدف برنامجه التدريبي المقترح في محاولة لتطـوير بعض المتغير ات البدنيـة و المستوى الرقمي للسباحين وذلك من خلال أداء التدريبات المقترحة باستخدام تدريبات الكروس

\section{الأسس العلمية التي تم مراعاتها عند وضع البرنامج التدريبي: -}

ا. أن يحقق البرنامج الأهداف الموضوعة لتنمية عناصر اللياقة البدنية الخاصة والمستوى

$$
\text { الرقمي للسباحين }
$$

r. . أن تتمشى محتويات البرنامج مع قدر ات السباحين دون التعارض للحمل التدريبي. r. ان تتشابه التدريبات المقترحة بقدر الإمكان مع الأداء الحركي والعمل العضلي بالنسبة

$$
\begin{aligned}
& \text { لجميع أجز اء الجسم (التدريب على طبيعة الأداء التنافسي). } \\
& \text { ع. تتويع محتويات البرنامج واتسامه بالمرونة. } \\
& \text { ๑. مر اعاة مبدأ تموج الحمل التدريبي. }
\end{aligned}
$$

7 . . مر اعاة التشكيل المناسب لحمل التدريب من حيث الثدة و الحجم وفترات الر احة. 


$$
\text { محددات البرنامج التدريبي: . يجب أن تمتزج تمرينات القوة بتمرينات الإطالة والاسترخاء. }
$$

حدد الباحث فترة تنفيـذ برنامجـه التـدريبي المقترح (^) أسـبوع تـدريبي، وافترض أنهـا مناسبة دن وجهة نظره لتحقيق هدف بحثه، وذلك بو اقع (ب) وحدات تدريبية أسبو عياً.

\begin{tabular}{|c|c|c|}
\hline القترة & متغيرات البرنامج التدريبي & م \\
\hline ^ اسبوع & مدة البرنامج التدريبي & .1 \\
\hline r وحدات اسبوعية & عدد الوحدات اليومية في الاسبوع &.$r$ \\
\hline G & زمن الوحدة التدريبية &.$r$ \\
\hline ق $r \wedge \wedge$. & أجمالي زمن البرنامج &.$\varepsilon$ \\
\hline ه ا - r \% من زمن الوحدة الكلي & زمن الاحماء & .0 \\
\hline ق & زمن التهائة & .9 \\
\hline$(1: Y)$ & ل لحمل. &.$V$ \\
\hline
\end{tabular}
جدول (0) محددات البرنامج التدريبي

تطبيق البرنامج:

تم تتفيذ البرنـامج التـدريبي خـلال فترة الاعداد الخـاص حيـث أدت المجموعـة التجريبيـة تدريبات الكروس فيت (cross fit) وأدت المجمو عة الضـابطة التدريبات التقليديـة بصـورة حـرة وكانت مدة البرنامج (1 أسابيع) بو اقع ثلاث وحدات أرضية للأسبوع خلال الفترة /9/9 1 ـ ب ال

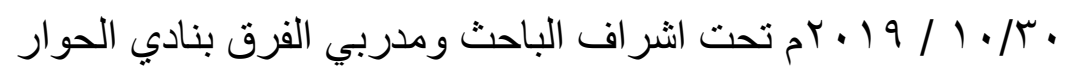

القياسات البعدية:

تم إجـر اء القياسـات البعديـة لمجموعـات البحـث بعـد استكمال البرنـامج التـدريبي، وبـفس الطريقة التي تم بها تطبيق القياسات القبيلة، وتحت نفس الظروف، وذلك خلال الفترة من / / | 1 / /

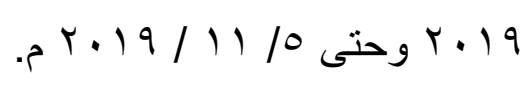
المعالجات الإحصائية: اسـتخدم الباحـث في المعالجـات الإحصـائية للبيانـات داخـل هـذه الدر اسـة برنـامج الحـزم Statistical Package For Social Science (SPSS) الإحصائية للعلوم الاجتماعية الإصدار (rT) مستعينًا بالمعاملات التالية: 


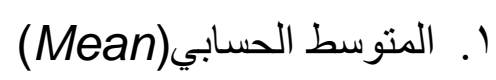

r. الانحر اف المعياري (Standard Deviation). r. اختبار (ت) لعينتين مرتبطتين من البيانات (Paired Sample t-Test).

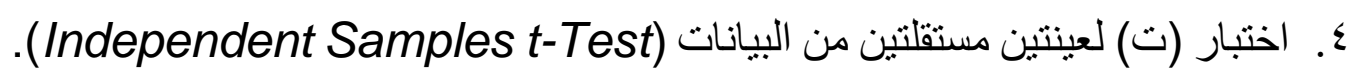

•. حجم التأثير (Effect Size) في حالة اختبار (ت): أ. باستخدام (ES) ويفسر طبقا لدحاكات كو هين.

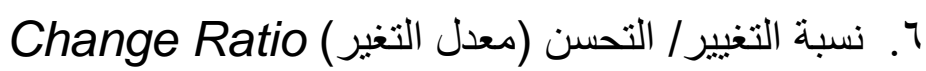

$1 \cdots x$ القياس البعدى - القياس القبلى - معير نسبة التحسن =

$$
\text { القياس القبلى }
$$

عرض ومناقشة نتائج البحث:-

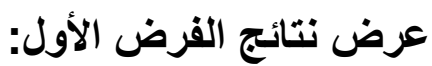

ينص الفرض الأول على أنـهـ :" توجد فروق دالـة إحصـائيًا بين القياسين القبلي والبعدي (المجموعة التجريبية) في المتغيرات قيل البحث لصالح القياس البعدي في كـلا من المتغيرات البدنية و المستوى الرقمي "؛ وللتحقق مـن صـحة الفرض الأول استخدم الباحث اختبـار (ت)

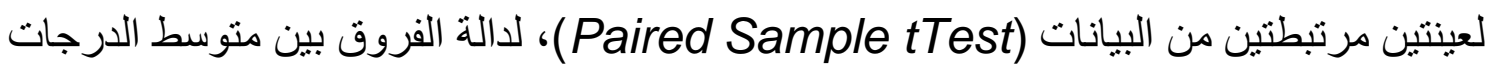

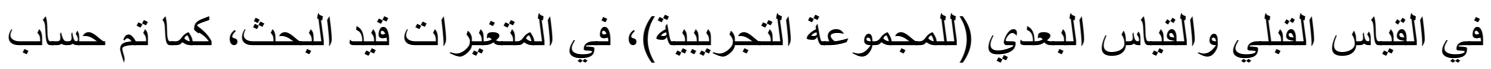

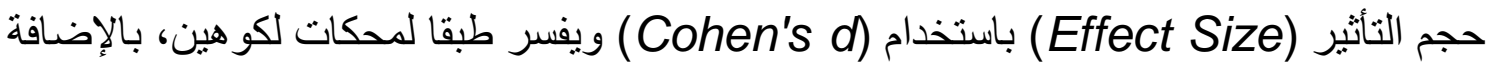

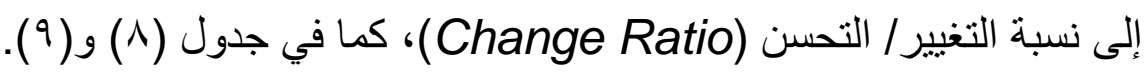
جدول (^) دلالة الفروق بين القياس القبلي والقياس البعدي (للمجموعة التجريبية) في

\begin{tabular}{|c|c|c|c|c|c|c|c|}
\hline \multirow{2}{*}{$\begin{array}{c}\text { التأثبر } \\
\text { Cohen' } \\
\text { s d }\end{array}$} & \multirow[b]{2}{*}{ 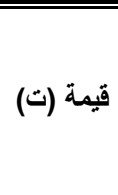 } & \multicolumn{2}{|c|}{ القياس البعدى } & \multicolumn{2}{|c|}{ القياس القبلى } & \multirow[b]{2}{*}{ القياس } & \multirow[b]{2}{*}{ المتفيرات } \\
\hline & & 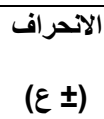 & المنتوسط & 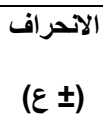 & $\begin{array}{c}\text { المتوسط) } \\
\text { (سن) }\end{array}$ & & \\
\hline 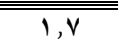 & $\mid \overline{P Y, V Y}$ & 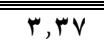 & 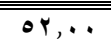 & PY, & 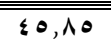 & كجم & اختبار قوة القبضة (اليدا الدفضلة) \\
\hline$r, \Lambda$ & $1 \varepsilon, 14$ & $r, 14$ & $1 \leqslant \Lambda, \wedge \leqslant$ & $1, \mathrm{va}$ & $1 \mu \Lambda, \ldots$ & كجم & اختبار القوة القصوى لعضلات الظهر \\
\hline$r, \varepsilon$ & $18, \ldots$ & $\varepsilon, \cdot r$ & $104, V Y$ & $r, r)$ & $1 \leqslant 0,10$ & كجم & الرجلين القوة القصوى لعضلات \\
\hline
\end{tabular}
المتغيرات قيد البحث 


\begin{tabular}{|c|c|c|c|c|c|c|c|}
\hline$r, 1$ & 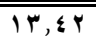 & $1,0 Y$ & $70,1$. & $\overline{r, V T}$ & $09,9$. & عدد & اختبار الجلوس من الرقود \\
\hline$\varepsilon, V$ & $r_{1,1}$ & r,rq & Or,, . & $1, \leqslant 9$ & $\varepsilon \cdot, r$ & عدد & اختبار الانبطاح المائل \\
\hline$\varepsilon, 9$ & $1 \cdot, 11$ & $1, V T$ & $v_{0,9}$. & $1, \leqslant 0$ & $\checkmark \wedge, 1$ & 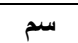 & الوثب العمودي \\
\hline 0,1 & $11, r v$ & $\cdot, .9$ & Y,VI & $\cdot, 14$ & $r, I Y$ & متر متر & الوثب العريض \\
\hline$r, \xi$ & $\Lambda, r$. & $\cdot, r r$ & $9, \leq 9$ & $\cdot, \wedge r$ & 8,79 & 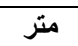 & دفع كرة طبيه \\
\hline$r, 0$ & $V, \varepsilon r$ & $1, \wedge 9$ & $77, \ldots$ & 8,14 & $0 \cdot, \varepsilon$ & عدد ع & اختبار الانبطاح المائل من الوقوف \\
\hline $1, \varepsilon$ & $r, r$. & $\cdot, Y \varepsilon$ & $\cdot, \wedge 4$ & $\cdot, .0$ & 1,1 . & دقيقه & سباحه ... ام فراشه \\
\hline
\end{tabular}

ولتحديد الدلالـة التطبيقيـة للمتغيـر المسـتقل علـي المتغيـر التـابع تـم حسـاب حجم التـأثير باستخدام باستخدام (Cohen's d) وتر اوحت قيم (Cohen's d) بين (ع , l) و( , (o) و هذا يدل على حجم تأثثر (ضخم Huge)

جدول (9) نسبة التحسن بين درجات (المجموعة التجريبية) في المتفيرات قيد البحث (ن= )

\begin{tabular}{|c|c|c|c|c|c|}
\hline التحسبة & القرق بين & متوسط القياس & متوسط القياس & القياس & 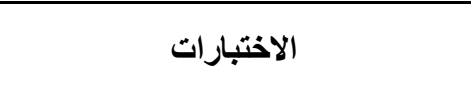 \\
\hline||$r, \leq 1$ & 7,10 & $0 Y, \ldots$ & $2 \leqslant \theta, \wedge \theta$ & كجم & اختبار قوة القبضة (اليد المفضلة) \\
\hline$\checkmark, \wedge T$ & $1 \cdot, \Lambda \varepsilon$ & $1 \leqslant \Lambda, \Lambda \leqslant$ & $1+\Lambda, \ldots$ & كجم & اختبار القوة القصوى لعضلات الظهر \\
\hline$V, 9 v$ & $11,0 \mathrm{~V}$ & $104, V Y$ & $1 \leq 0,10$ & كجم & الرجلين القوة القصوى لعضلات \\
\hline $1 \leqslant, \leqslant 1$ & $\Lambda, Y \cdot$ & 90,1 . & $07,9$. & عدد & اختبار الجلوس من الرقود \\
\hline$r 1, \cdot r$ & 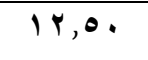 & $\Delta r, \Lambda$. & $\varepsilon \cdot, r$ & عدد & اختبار الانبطاح المائل \\
\hline $11, \leqslant 0$ & $\vee, \Lambda$. & $v_{0}, q$. & $\because \Lambda, 1$. & سم & الوثب العمودي \\
\hline$r V, O r$ & $\cdot, 01$ & $r, Y$, & $r, I r$ & متر & الوثب العريض \\
\hline$r r, \varepsilon r$ & $1, \wedge$ & $9, \leqslant 9$ & $v, 79$ & متر & دفع كرة طبيه \\
\hline$r \cdot, 90$ & 10,7 & $74, \ldots$ & $0 \cdot, \leqslant$ & عدد & اختبار الانبطاح المائل من الوقوف \\
\hline$r_{1}, \mathrm{~V}$ & $\cdot, Y \leqslant-$ & $\cdot, \wedge \mathrm{r}$ & 1,1 . & دقيقه & سباحه . . ام فراشه \\
\hline
\end{tabular}

عرض نتائج الفرض الثاني:

ينص الفرض الثاني على أنه :" توجد فروق دالة إحصائيًا بين القياسين القبلي والبعدي (المجموعة الضابطة) في المتغيرات قيد البحث لصالح القيـاس البعدي في كـلا مـن المتغيرات 
البدنية و المستوى الرقمي "؛ وللتحقق من صـحة الفرض الثناني استخدم الباحث اختبـار (ت) لعينتين مرتبطتنين من البيانات (Paired Sample tTest)، لدالة الفروق بين منوسط الدرجات

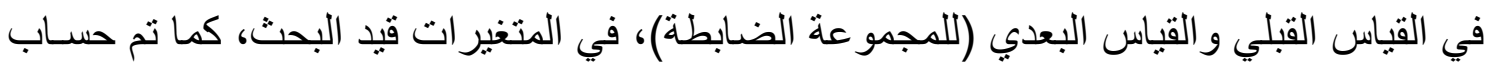
حجم الثأثير (Effect Size) باستخدام (Cohen's d) ويفسر طبقا لهحكات لكو هين، بالإضافة إلى نسبة التغيير / التحسن (Change Ratio)، كما في جدول ( • (') و( ' ( )

جدول ( • 1) دلالة الفروق بين القياس القبلي والقياس البعدي (للمجموعة الضابطة) في المتغيرات قيد البحث

\begin{tabular}{|c|c|c|c|c|c|c|c|}
\hline \multirow{2}{*}{$\begin{array}{c}\text { ججم التأثير } \\
\text { Cohen's } \\
\text { d }\end{array}$} & \multirow[b]{2}{*}{ ق قتيمة } & \multicolumn{2}{|c|}{ القياس البعدي } & \multicolumn{2}{|c|}{ القياس القبلي } & \multirow[b]{2}{*}{ والقياس } & \multirow[b]{2}{*}{ المتغيرات } \\
\hline & & 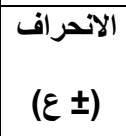 & المتوسط & 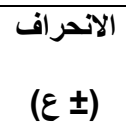 & المتوسط) & & \\
\hline $1, r$ & $r, V r$ & $r, 1$. & $\leqslant \vee, O$. & $1,7 \varepsilon$ & $\varepsilon \leqslant, r$. & كجم & المفضبلة) قوة القبضة (اليدا \\
\hline 1,7 & $\varepsilon, \wedge \wedge$ & $r, \wedge q$ & $1 \leqslant r, \leqslant V$ & $r, r$ & $\mid r \Lambda, Y 4$ & كجم & الظهز القوة القصوى لعضلات \\
\hline$r, \mathrm{~V}$ & 7,71 & $r, \leqslant 0$ & $101,0 \leqslant$ & $\cdot, \wedge \varepsilon$ & $1 \leqslant \varepsilon, \varepsilon$. & كجم & الرجلين القوة القصوى لعضلات \\
\hline $1, \cdot$ & $r, \xi 1$ & $\varepsilon, 11$ & 09,4 . & r, ro & $00, \Lambda$. & عدد & اختبار الجلوس من الرقود \\
\hline 0,1 & $11, \mathrm{V \Lambda}$ & $1, \leqslant 1$ & $\varepsilon \vee, \ldots$ & $1, \varepsilon$. & $r q, \wedge$. & عدد & اختبار الانبطاح المائل \\
\hline 1,0 & $r, \cdot r$ & $1, \lambda 1$ & $v \cdot, \Lambda$. & $1, \wedge q$ & $\because \Lambda, \ldots$ & سم & الوثب العمودي \\
\hline 1,1 & $r, \leqslant Y$ & $\cdot, 1$. & 5,19 & $\cdot, 1 Y$ & $r, \cdot \Lambda$ & متر & الوثب العريض \\
\hline $1, \mathrm{v}$ & $0, \wedge 0$ & $\cdot, 71$ & $\Lambda, 74$ & $\cdot, \mathrm{VV}$ & $v, \leqslant q$ & متر & دفع كرة طبيه \\
\hline$r, \mathrm{~V}$ & $9,1$. & 1,74 & rr,q. & 0,44 & $\leqslant 9,7$ & عدد & الوقتبار الانبطاح المائل من \\
\hline$\cdot, \mu$ & $\cdot, \mathrm{V}_{1}$ & $\cdot, ., 0$ & $1, \cdot 9$ & $\cdot, 11$ & $1,1 Y$ & دقيقه & سباحه . . . ام فراشه \\
\hline
\end{tabular}

ولتحديد الدلالة التطبيقية للمتغير المستقل على المتغير التابع نم حساب حجم التأثير باستخدام

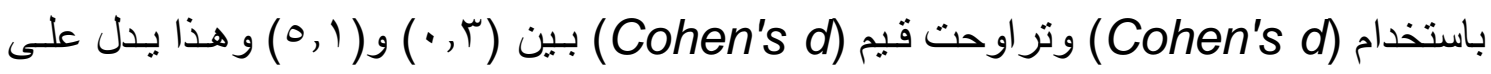
حجم تأثثير(منعدم) إلى (ضخم (Huge). 
جدول (1 1) نسبة التحسن بين درجات (المجموعة الضابطة) في المتغيرات قيد البحث) (ن)

\begin{tabular}{|c|c|c|c|c|c|}
\hline التحسبة & القياسين بين & القياس & القتياس & القياس & الاختبارات \\
\hline $\bar{V} V, Y Y$ & $\overline{r, r} \cdot$ & $\varepsilon V, 0$ & \&ะ,r. & كجم & اختبار قوة القبضة (اليد المفضلة) \\
\hline$r, \cdot \varepsilon$ & $\varepsilon, Y$ & $1 \leqslant Y, \leqslant V$ & $1+\Lambda, Y T$ & كجم & اختبار القوة القصوى لعضلات الظهر \\
\hline$\varepsilon, 9 \leqslant$ & $V, 1 \leq$ & $101,0 \leq$ & $1 \leqslant \leqslant, \leqslant$. & كجم & اختبار القوة القصوى لعضلات الرجلين \\
\hline$Y, Y V$ & $r, 0$. & $\Delta q, r$. & $\Delta \Delta, \Lambda$ & عدد & اختبار الجلوس من الرقود \\
\hline $11, .9$ & $\checkmark, r \cdot$ & $\xi V, \ldots$ & $r q, \Lambda$. & عدد & اختبار الانبطاح المائل \\
\hline$\varepsilon, 1 Y$ & $r, \Lambda$. & $V \cdot, \Lambda$ & $\checkmark \wedge, \ldots$ & سم & الوثب العمودي \\
\hline $0,7 \leqslant$ & $\cdot, 1 r$ & $r, 19$ & $r, \cdot \Lambda$ & 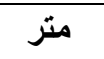 & الوثب العريض \\
\hline 10,79 & $1,1 \mathrm{~V}$ & $\Lambda, 74$ & $v, \leqslant 9$ & متز & دفع كرة طبيه \\
\hline$r \checkmark, \wedge !$ & $\boldsymbol{I r}, \boldsymbol{r}$ & Ir, q. & «१,१. & عدد & اختبار الانبطاح المائل من الوقوف \\
\hline$r, 0$. & $\cdot, \cdot r_{-}$ & $1, .9$ & $1,1 Y$ & دقيقه & سباحه . . ام فراشه \\
\hline
\end{tabular}

عرض نتائج الفرض الثالث:

ينص الفرض الثالث على أنه :" توجد فروق دالة إحصائيًا بين القياس البعدي (للمجموعة التجريبية) والقياس البعدي لمجموعة (للمجموعة الضسابطة) في المتغيرات قيد البحث لصـالح القياس البعدي للمجموعة التجريبية."؛ وللتحقق من صحة الفرض الثالث استخدم الباحث اختبـار (ت) لعينتين مستقلتين من البيانـات (Independent Samples tTest)، لدالـة الفروق بين متوسط الدرجات في القياس البعدي (للمجموعة التجريبية) و القياس البعدي لمجموعـة (للمجموعـة الضـابطة)، في المتغير ات قيد البحـ، كمـا تم حسـاب حجم التأثثر (Effect Size) باسـتخدام Change ( ويفسر طبقا لمحكات لكوهين، بالإضافة إلى نسبة التغيير / التحسن (Cohen's d) Ratio 
جدول (Y I) دلالة الفروق بين القياس البعدي (للمجموعة التجريبية) والقياس البعدي لمجموعة

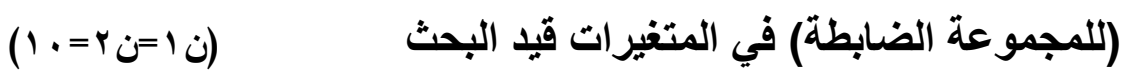

\begin{tabular}{|c|c|c|c|c|c|c|c|}
\hline \multirow{2}{*}{$\begin{array}{c}\text { حجم التأثير } \\
\text { Cohen's } \\
d\end{array}$} & \multirow{2}{*}{ قيمة } & \multicolumn{2}{|c|}{ المجموعة الضابطة } & \multicolumn{2}{|c|}{ المجموعة التجريبية } & \multirow[b]{2}{*}{ | القياس } & \multirow[b]{2}{*}{ المتغيرات } \\
\hline & & 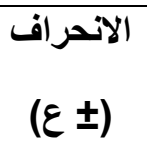 & المتوسط & 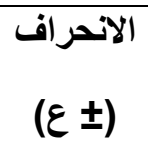 & المتوسط & & \\
\hline 1,0 & $r, 11$ & $r, 1$. & $\leqslant V, 0$ & $r, r V$ & or,... & 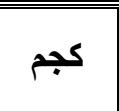 & (اختبار قوة القبضة \\
\hline$r, r$ & $\varepsilon, V$. & $r, \wedge q$ & $1 \leq Y, \leqslant V$ & $r, 19$ & $1 \leq \Lambda, \Lambda \varepsilon$ & 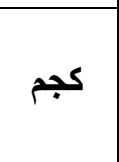 & الظتبار القوة لعضلات \\
\hline 1,0 & $r, \cdot q$ & $r, \leqslant 0$ & $101,0 \leq$ & $1, \cdot r$ & $107, \mathrm{Vr}$ & 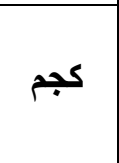 & القتبوى لعضلار القوة \\
\hline$r, \cdot$ & $\varepsilon, 1 \wedge$ & $r, 11$ & $\bullet q, r$. & $1,0 r$ & $70,1$. & عدد & الرقتبار الجلوس من \\
\hline$r, 1$ & 7,7 & $1, \leqslant 1$ & $\varepsilon V, \ldots$ & $r, r q$ & or,$\Lambda$. & عدد & المائبار الانبطاح \\
\hline$r, \cdot$ & $7, \leqslant \leqslant$ & $1, \wedge 1$ & $V \cdot, \Lambda \cdot$ & $1, V r$ & $v_{0}, q$. & 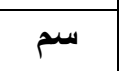 & الوثب العمودي \\
\hline 0,7 & $11, \wedge r$ & $\cdot, 1$. & $r, 19$ & $\cdot, \cdot 9$ & $r, Y I$ & متر متر & الوثب العريض \\
\hline 1,1 & $r, \Lambda$. & $\cdot, 71$ & 1,79 & $\cdot, \mu Y$ & $9, \leqslant 9$ & متر & دفع كرة طبيه \\
\hline 1,1 & $r, q$. & 1,79 & $9 r, q$. & $1, \wedge 9$ & $79, \ldots$ & عدد & المائبل من الأوقوف \\
\hline $1, \varepsilon$ & $r, \cdot \varepsilon$ & $\cdot, \cdot 0$ & $1, .9$ & $\cdot, r \varepsilon$ & $\cdot, \wedge \uparrow$ & دقيقه & 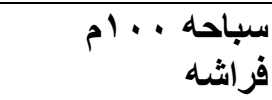 \\
\hline
\end{tabular}

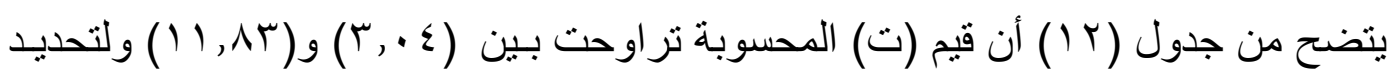

الدلالة التطبيقية للمتغير المستقل على المتغير التـابع تـم حسـاب حجم التـأثنير باسـتخدام باسـتخدام

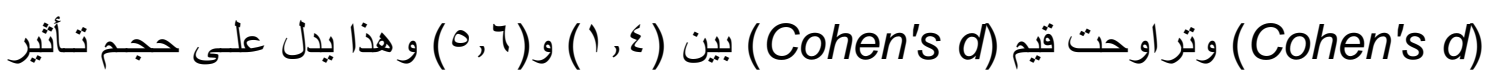
(كبير جدا Very Large ) إلى (ضخم Huge). 
جدول (r I) الفروق في نسبة التحسن بين (المجموعة التجريبية) مجموعة (المجموعة الضابطة) في المتغيرات قيد البحث

\begin{tabular}{|c|c|c|c|c|c|c|c|}
\hline \multicolumn{2}{|c|}{ القروق بين } & \multicolumn{2}{|c|}{ المجموعة الضابطة } & \multicolumn{2}{|c|}{ المجموعة التجريبية } & \multirow[b]{2}{*}{ والقياس } & \multirow[b]{2}{*}{ المتغير ات } \\
\hline نسبّة & القيّاسين & التحسبة & القباسط البعدي & التحسبة & القتوسط البعدي & & \\
\hline 7,19 & $\varepsilon, 0$. & $V, r r$ & $\varepsilon V, 0$. & $|r, \varepsilon|$ & $\Delta r, \ldots$ & 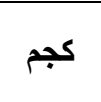 & اختبار قوة القبضة (اليد \\
\hline$\varepsilon, \wedge r$ & $\neg, r v$ & $r, \varepsilon$ & $1 \leq r, \varepsilon V$ & $\vee, \wedge \neg$ & $1 \leq \Lambda, \Lambda \leq$ & 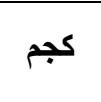 & اختبار القوة القصوى لعضلات \\
\hline$r, \cdot r$ & 0,11 & $\varepsilon, 9 \leq$ & $101,0 \leq$ & $v, 9 v$ & $107, V Y$ & 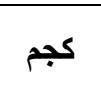 & اختبار القوة القصوى لعضلات \\
\hline$\Lambda, 1 \leq$ & $\bullet, \wedge$. & $Y, Y V$ & $\Delta q, \mu$ & $\mid \leq, \leq 1$ & $70,1$. & عدد & اختبار الجلوس من الرقود \\
\hline$M Y, q r$ & $\bullet, \Lambda$. & $11, \cdot 9$ & $\leq V, \ldots$ & $r 1, r$ & $\Delta Y, \Lambda$. & عدد & اختبار الانبطاح المائل \\
\hline$V, r r$ & 0,1 & $\varepsilon, 1 Y$ & $V \cdot, \wedge \cdot$ & $11, \varepsilon 0$ & $v 0,9$. & 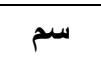 & الوثب العمودي \\
\hline$Y 1, \wedge q$ & $\cdot, O r$ & $0,7 \leq$ & $r, 19$ & $r V, \diamond r$ & $r, V_{1}$ & متر & الوثب العريض \\
\hline $\mathrm{V}, \mathrm{VV}$ & $\cdot, \lambda r$ & 10,77 & $\Lambda, 77$ & $r r, \varepsilon r$ & $9, \varepsilon 9$ & متر & دفع كرة طبيه \\
\hline$\varepsilon, 1 \leq$ & $r, 1$. & $Y q, \wedge 1$ & $9 r, q$. & $r \cdot, 90$ & $77, \ldots$ & عدد & اختبار الانبطاح المائل من \\
\hline $19, Y 1$ & $\cdot, r T=$ & $r, 0$. & $1, \cdot 9$ & YI,VA & $\cdot, \wedge \mathrm{r}$ & دقيقه & سباحه . . ام فراشه \\
\hline
\end{tabular}

يتضـح مـن جدول رقـم (^) وجـود فروق دالـة إحصـائيا بـين القياسـين القبلـي والبعدي

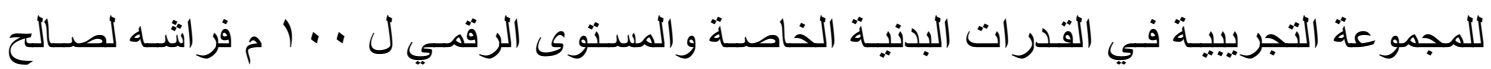

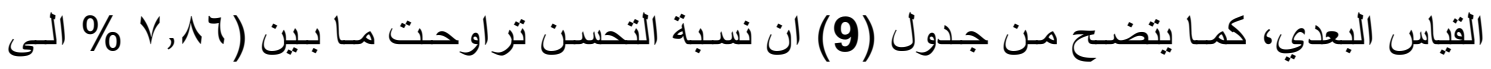
31.02\%)، حيث كانت أعلى نسبة تحسن فى الاختبار ات الانبطاح المائل (r . , اr \%)، وكانت

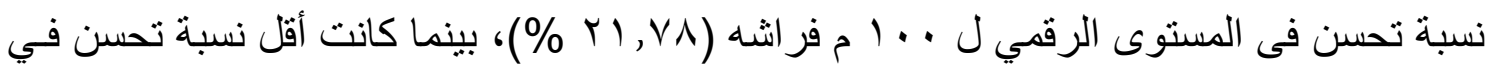

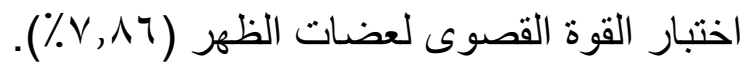


كما يتضح من جدول (^) (9) وجود فاعلية مناسبة للبرنامج ويرجع الباحث هذ التحسن الى طبيعـة تدريبات الكروس فيـت (cross fit) المقترحسة و المقنتـة علميـا و الموجهـة بصـورة مباشرة للهدف التدريبي حيث أدت الى تحسن القدرات البدنية الخاصة وكذلك و المستوى الرقمي ل

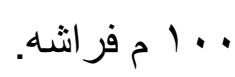

كما يعزى الباحث هذا التحسن إلى فاعلية تأثثر تدريبات الكروس فيت (cross fit) التي شملت جميع عضلات الجسم وكذلك التركيز على العضلات العاملة في سباحه الفر اشة، ممـا كـان لها تأثير إيجـابي على تحسن قوة عضـلات الرجلين و الظهر وكذلك القدرة العضـلية للرجلين و الـذر اعين وأيضـا التحمـل العضـلي للـرجلين و الـذر اعين وبـاقي القـدر ات البدنيـة الخاصـة لـدى السباحين.

ومن خلال العرض السابق للنتائج ومناقتـتها يتضـح صـحة الفرض الأول و الذي يـص على: توجد فروق دالة إحصائيًا بين القياسـين القبلي والبعدي (المجموعـة التجريبيـة) لصسالح القياس البعدي في كلا من المتغيرات البدنية و المستوى الرقمي . مناقشة نتائج الفرض الثاني:

يتضح من جدول ( • ())، وجود فروق دالة إحصائيا بين القياسين القبلي و البعدي للمجموعة الضابطة في القدر ات البدنية الخاصة و المستوى الرقمي ل . . 1 م فر اشه لصالح القيـاس البعدي،

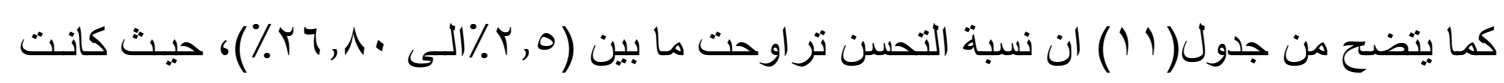

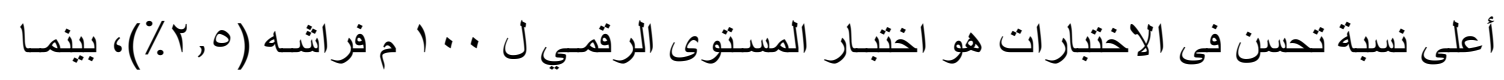
كانت أقل نسبة تحسن فى اختبار اختبار الانبطاح المائل من الوقوف (^, ؟Y٪).

ويرجع الباحث هذه النتائج الى البرنامج التقليدي للمجموعة الضابطة، وأيضـا كفـاءة لاعبي المجموعة الضـابطة حيث أن الانتظام والاسـتمرار في التـدريب بالإضـافة الـى التتـافس المستمر لتقديم أفضل مستوى بدنى ومهارى كان له أثر كبير فى رفع مستوى القدرات البدنيـة و المسـتوى

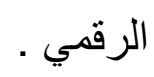

ومن خلال العرض السابق للنتائج ومناقثتنها يتضح صحة الفرض الثاني و الذي ينص على: توجد فروق دالة إحصائيًا بين القياسين القبلي والبعدي (المجموعـة الضـابطة) لصـالح القيـاس ولي البعدي فى كلا من المتغيرات البدنية والمستوى الرقمي لوفي 
يتضح من جدول (Y Y)، (T I ) وجود فروق دالة إحصائيا بين القياسين البعديين للمجموعـة التجريبية و الضـابطة فحى القدر ات البدنيـة الخاصـة والمسـتوى الرقمـي ل . . ا م فر اشـهـ لصـالح القياس البعدي للمجموعة التجريبية، كما يتضح من جدول (r I ) حصول المجموعة التجريبية على نسب تحسن للقدرات البدنية الخاصـة و المسـتوى الرقـي ل . . 1 م فر اثــه أعلى مـن المجموعـة الضـابطة، وان الفرق بين نسبة تحسـن المجموعـة التجريبيـة ونسبة تحسـن المجموعـة الضــابطة

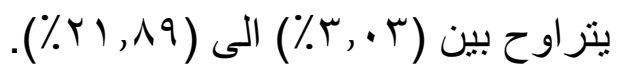

ويرجع الباحث نسبة التحسن الناتجة لصالح المجموعة التجريبية عن المجموعـة الضـابطة الى فاعلية تـدريبات الكروس فيـ (cross fit) التي سـاعدت على تقويـة عضـلات الذر اعين و الرجلين و الظهر بصفة خاصة و عضلات الجسم بصفه عامة حيث ان تدريبات الكروس فيـت ( ( احتوت على عدد من التدريبات التي تسهم في تنمية بعض عناصر اللياقة البدنية مثل (القوة العضلية، التحمل العضلي ،القوة المميزة بالسر عة ،الرشاقة) و التي بدور ها أدت إلي تحسين المستوى الرقمي لسباحه الفر اثة لاعتماد هذه المهارة على قوة عضلات الذر اعين و الظهر وكذلك الرجلين.

كما يعزى الباحث هذا التحسن الى احتواء تدريبات الكروس فيت (cross fit) الذي طبق على المجمو عة التجريبية على تدريبات مشابهة للأداء في سباجه الفر اشة وفى نفس اتجـاه العمل العضلي الذي أدى الى تحسن المستوى الرقمي للمجموعة التجريبيـة بدرجـة أكبـر مـن المجموعـة الضابطة

ومن خلال العرض السابق للنتائج ومنافثتها يتضح صحة الفرض الثالث و الذي ينص على: توجد فروق دالة إحصائيًا بين القياس البعدي (للمجموعة التجريبية) والقياس البعدي لمجموعة (للمجموعة الضابطة) لصالح القياس البعدي للمجموعة التجريبية.

ونجد ان نتائج هذه الدراسة تتفق مـع مـا توصـل إلبـه كـلا مـن وجدى الفـاتح ( . 9 9

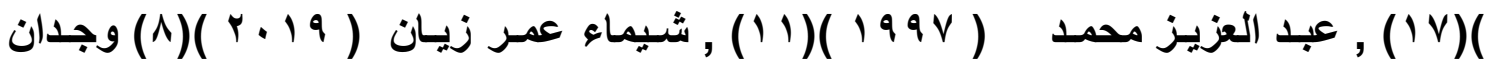

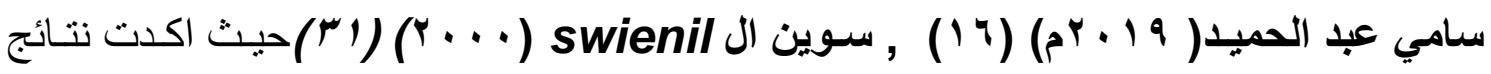
هذه الأبحاث على ان البرامج التدريبية المقننة ساعدت على تطوير القدرات البدنيـة الامـر الذَى أدى بدورة الى تحسن في الأداء و كذلك اشارت الى أهمية تتمية القوة العضلية و الى أهميـة القوة 
المخرجة اثناء السباحة لكلا من عضلات الجذع و الرجلين و يتفق ذلك مع ما اظهرته نتائج جدول

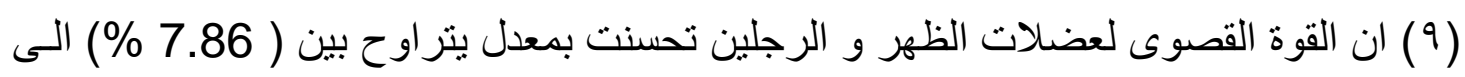

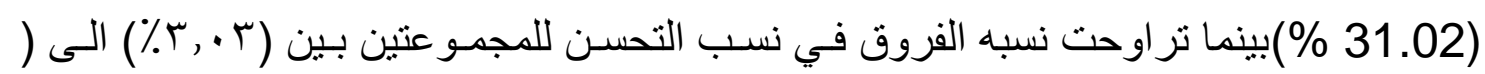
$(\%), \wedge 9$

كما تتفق نتائج البحث الحالي مع ما وضحة كل من على البيك ( \& 99 1 ) ) و محمد القط (

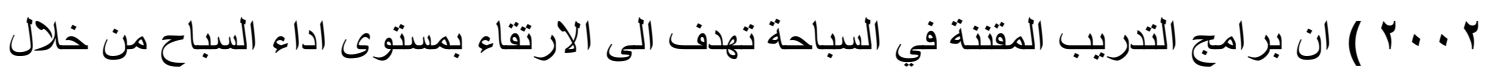

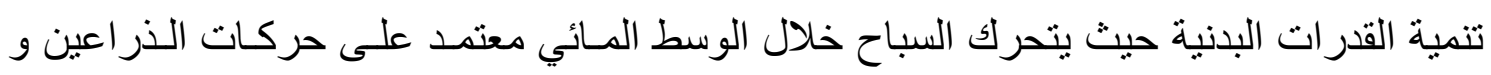

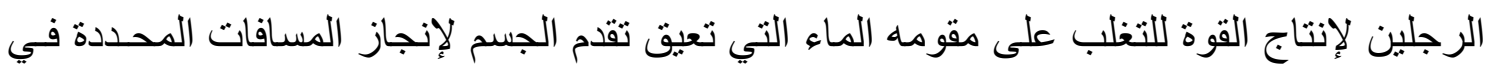

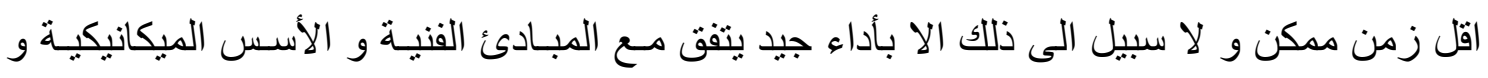

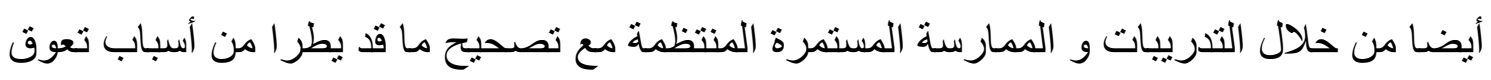

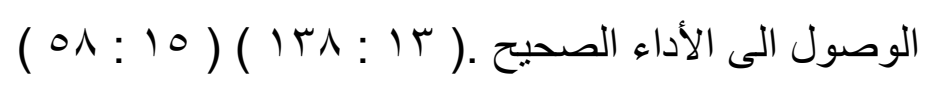

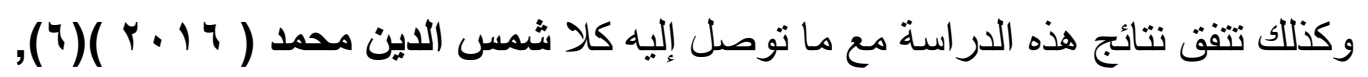

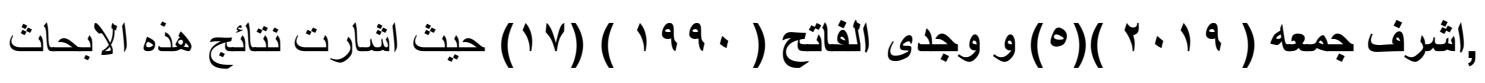

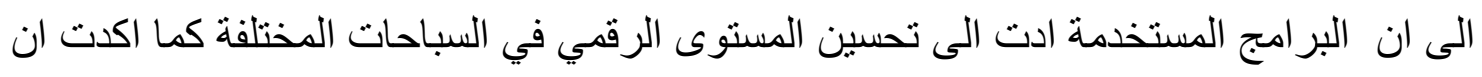

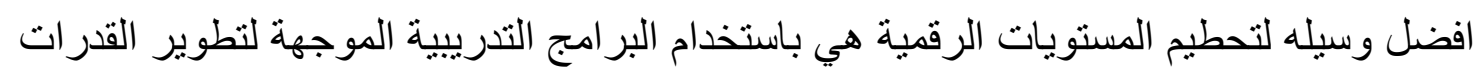

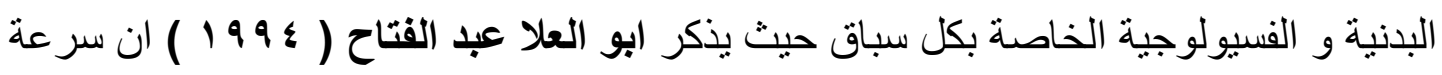

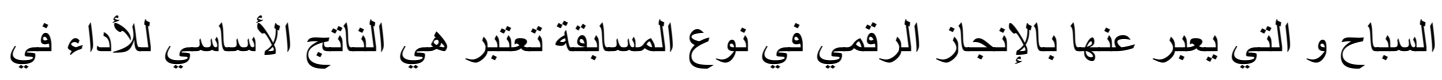

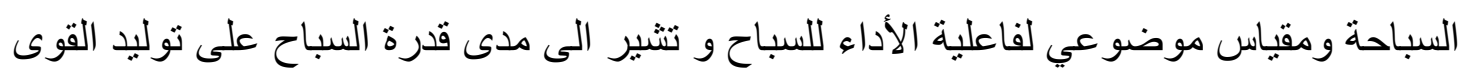

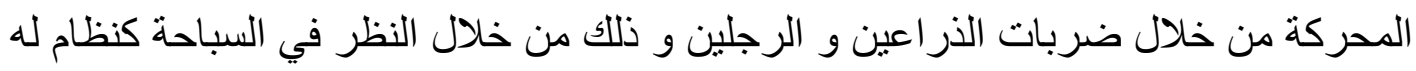

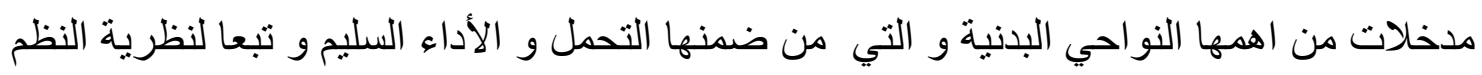
فان أي تعديلات او تطوير في المدخلات قد يؤدى الى تحسين و تطوير النواتج و الانجاز الرقمي $(10: r)$

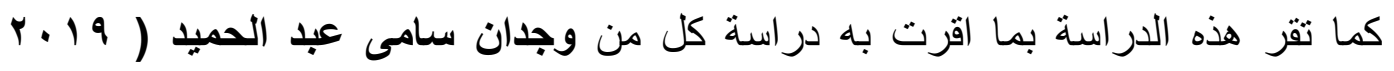

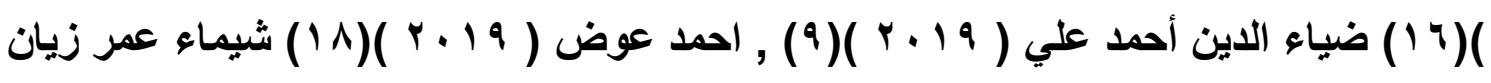

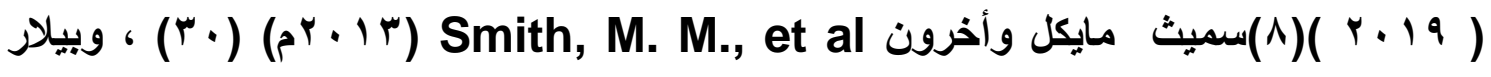

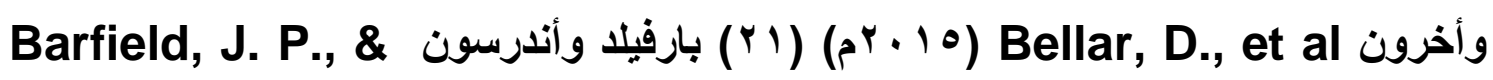




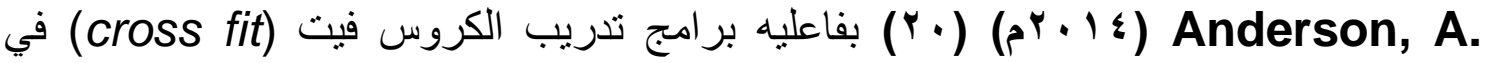
تطوير كل من القدرات البدنية و المستويات الرقمية للاعبي بصورة اكثر كفاءة و ذلك لما تحتويه من تدريبات متتوعهو موجهه لنطوير القدريات البننية المؤثرة في الأنشطة المختلفة بصورة اكثر

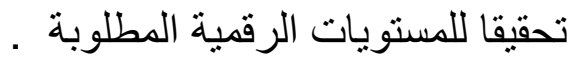

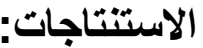

من خلال الأهداف و الفروق التي وضعت للبحث وفي حدود عينة البحث و المنهج المستخدم

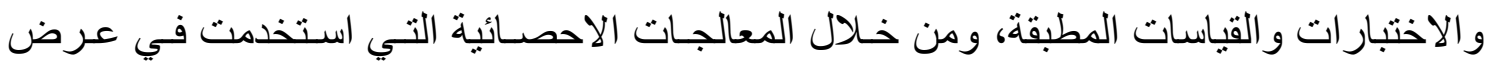

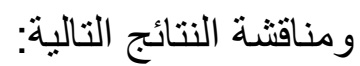
1ـ أثر البرنامج المقترح تأثثرا ايجاييـا في تطوير بعض القدرات البدنيـة الخاصـة بسباحة

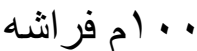
r- أثر البرنامج التنديبي المقترح تأثثير ا ايجابيا في تطوير وتحسين المستوي الرقمي بسباحة

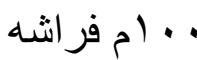
كـ تفوقت المجموعـة التجرييـة التي استخدمت الكروس فيت (cross fit) في التدريب الأرضي على المجموعة الضـابطة التي استخدمت التـدريبات التقليديـة في القدرات البننيـة الخاصة و المستوي الرقمي لسباحة ... ام فراشه

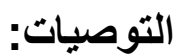

استتادا إلى النتائج و الاستخلاصـات التي توصل إليها الباحث من خـلال هذا البحث يوصي

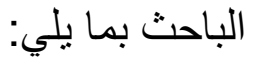
ا ـ ضرورة الاهتمام من قبل العاملين في المجال العلمي التطبيقي باستخدام تدريبات الكروس فيت (cross fit) لما لها من مردود فعـال علـي تحسين وتطوير القدرات البدنيـة الخاصـة و المستوي الرقمي لطرق السباحة المختلفة.

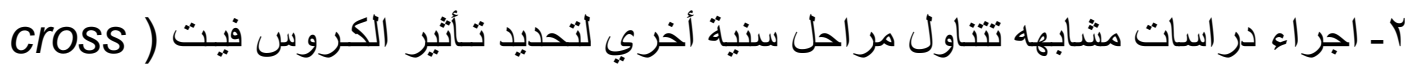
(fit ) مقارنة بتأثير تدريبات الأرضي التقليدية لدي السباحين و السباحات. rـ إجر اء المزيد من البحوث لتحديد تأثير تدريبات الكروس فيت (cross fit) على للجهاز العصبي والاستثارة العصبية للمر احل التدرييية والعمرية المختلفة وعلى كلا الجنسين. 
ع - إجر اء المزيد من البحوث على تدريبات الكروس فيت (cross fit) مع أساليب أو وسائل تدريبية مختلفة أثناء برامج التدريب المختلفة على متغيرات بدنية لدربية وفسيولوجية وبيوكيميائية

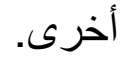

$$
\text { المراجع }
$$

- 1 -

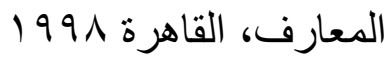

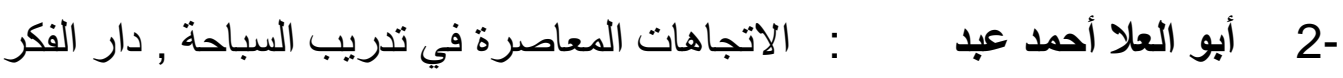

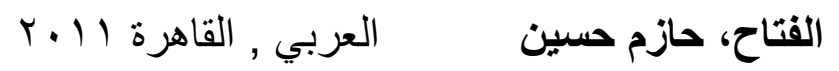
سالم

-3 أبو العلا عبد الفتاح تدريب السباحة للمستويات العليا، دار الفكر العربي،

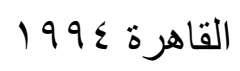

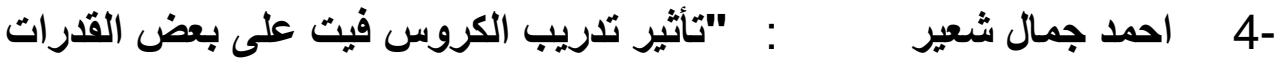

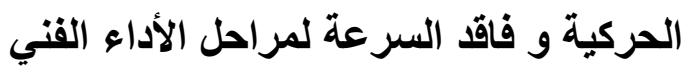

والمستوى الرقمي لمتسابقي الوثب الثلاثي " المجلة

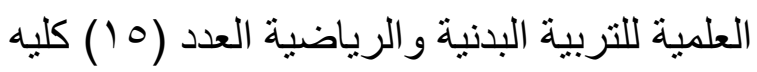

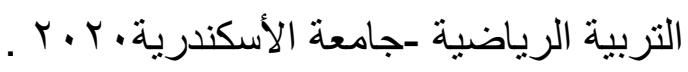

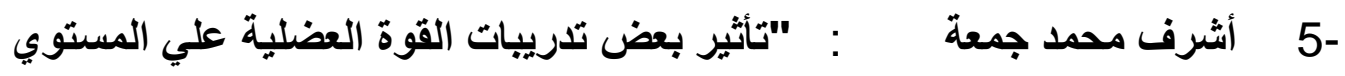
الرقمي لسباحة الرقمي لسباحة الزعانف" المجلة

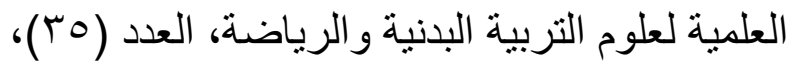

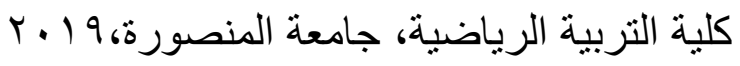

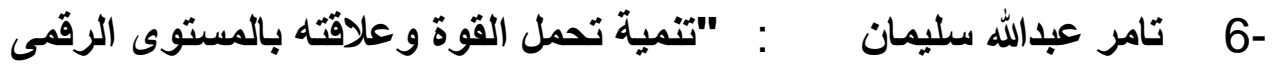
للسباحين ناشئين" رسالة ماجستير غير منشورة كلية

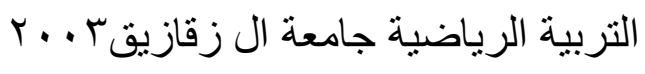
"تأثير تمرينات الحقيبة البلغارية على المتغيرات التهات البدينة والمستوى الرقمي لسباحي . . 1 متر فراشه 7تحت ب ا سنه " مجلة جامعة مدينة السادات للنربية 


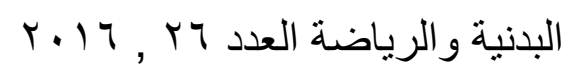

"فاعلية تلريبات الكروس فيث على بعض المتغيرات 8البدنية والفسيولوجية والإنجاز الرقمي لناشئات الوثب

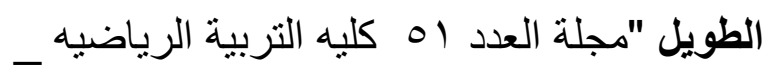

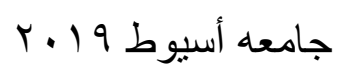

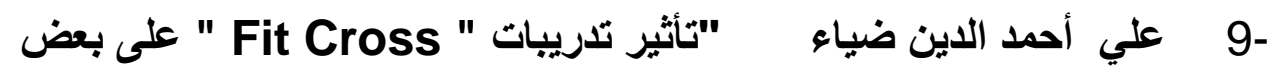
المتغيرات البذنية و المهارات الأساسية لليد غير المفضلة لدى أشبال كرة اليد " مجلة أسبوط لعلوم و فنون التربية الرياضية العدد اه كليه التربية الرياضية

$$
\text { _ جامعه أسيوط } 9 \text { ـ } 19
$$

التدريب الاثقال _ القوة العضلية (تصميم بر امج القوة 10وتخطيط الموسم التدريبي) , طا , الاستاذ للكتاب وناريمان الخطيب

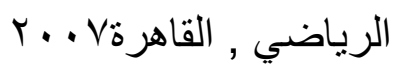

"تأثير برنامج للتدريب الأرضي على المستوى الرقمي 11 عبد العزيز محمد عبد لسباحي المنيا" ، رسالة ماجستير ، غير منشورة ، العزيز

كلية التربية الرياضية ، جامعة المنيا. و 199

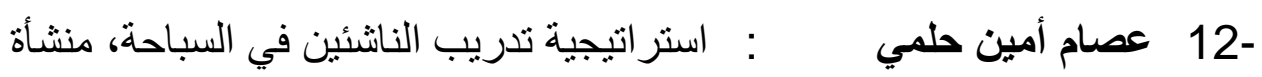
المعارف، المن،

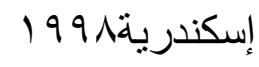

تخطيط التدريب الرياضي، طا رمنشأه المعارف 13الاسكندرية 1994

$$
\begin{aligned}
& \text { : الأسس العلمية لتدريب الرياضات المائية" , جامعة }
\end{aligned}
$$

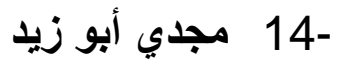

$$
\begin{aligned}
& \text { الإسكندرية .كلية التربية الرياضية أبو قير ه . . ب }
\end{aligned}
$$$$
\text { ، فيولوجيا الرياضة وتدريب السباحة الجزء الأول : }
$$

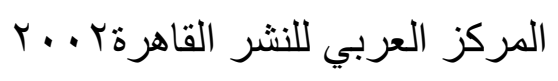

-16 وجدان سامي عبد الحميا : "تأثير تدريبات الكروس فيت علي بعض المتغيرات

الفسيولوجية والمستوي الرقمي لسباحي ، . . عتر" 


$$
\begin{aligned}
& \text { حره دكتور اه غير منشورة، كلية التربية الرياضية، }
\end{aligned}
$$

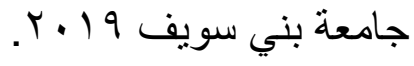

$$
\begin{aligned}
& \text { 17 وجدي مصطفى الفاتح أتثير برنامج تلريب (ارضى - مائي) مقترح على } \\
& \text { تقدم المستوى الرقمى لسباحة الزحف على البطن" } \\
& \text { رسالة ماجستير، غير منشورة، كلية التربية الرياضية ، }
\end{aligned}
$$

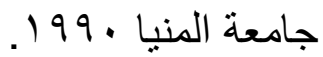

ثانيا : المراجع الاجنبيه :

18- Awed, A

19- Babiash, P. E.

20- Barfield, J. P., \& Anderson, A.

21- Bellar, D., Hatchett, A., Judge, L. W., Breaux, M. E., \& Marcus, L.

22- Borras, P. A., Herrera, J., \&
: "Effectiveness of Cross Fit drills on muscular endurance and Consecutive attempts cases for youth weightlifters "International Journal of Sports Science and Arts, 3(03) , 19-43, 2019.

Determining the energy expenditure and relative intensity of two cross fit workouts, Doctoral dissertation, and 2013.

: Effect of Cross $\mathrm{Fit}^{\mathrm{TM}}$ on health-related physical fitness: A pilot study, Journal of Sport and Human Performance, 2(1). 2014

"The relationship of aerobic capacity، anaerobic peak power and experience to performance in Cross Fit exercise" Biology of sport, 32(4) , 315. 2015.

: "Effects of cross fit lessons in physical education on the aerobic capacity of 
Ponseti, F. J. c.

24- Ernest W. Maglischo

25- Greag Glassman

26- Jeffery, Christine young students "Journal of Physical Education \& Health-Social Perspective, 6(10), 5-11. 2017.

23- Dawson, Marcelle : "Cross Fit: Fitness cult or reinvented institution?." International review for the sociology of sport 52.3 361-379. 2017.

: Swimming fastest ,the essential performance on technique, training and program designe ,Human kinetics , usa 2003

Cross Fit Level 1 Training Guide " Cross Fit Incorporated, 2017

: Cross Fit effectiveness on fitness levels and demonstration of successful program objectives. Arkansas State University, 2012.

27- Maté-Muñoz, J. L., : Muscular fatigue in response to different Lougedo, J. H., modalities of Cross Fit sessions. PloS Barba, M., García- one, 12(7), 2017.

28- Paine,J.,Uptgraft, : Cross Fit study. Command and General J., \& Wylie, R. Staff College, 1-34. 1,2010.

29- Reza

: Effects of 4 weeks of cross-fit and Dehghanzadeh , traditional training during pre-season Hiwa preparation period on young soccer Rahmani,Sajad players physical fitness, Conference: 11th Ahmadizad International Congress on Sport Sciences At: Iran, Tehran,2018. 
30- Smith, M. M., : Cross fit-based high-intensity power Sommer, A. J., $\quad$ training improves maximal aerobic fitness Starkoff, B. E., \& and body composition. J Strength Cond Devor, S. T Res, 27(11), 3159-3172. 3171. 2013.

31- Swain . ell

: Arm \&leg power output in swimming during simulated swimming physiology of exercise, de Montfort university Bedford, 2000 